\title{
Prevalence of multiple sclerosis in a south London borough
}

\author{
EDWARD S WILLIAMS, RONALD O MCKERAN
}

\begin{abstract}
A survey of multiple sclerosis in the London Borough of Sutton, population 169600 , yielded 195 cases, giving an overall prevalence of 115/100 000. This is the third highest prevalence for a first survey of a geographical area in the United Kingdom, exceeded only by $127 / 100000$ in north east Scotland and 134/100 000 in Shetland. On the classification system of Allison and Millar, three quarters of the cases were classified as probable multiple sclerosis, $15 \%$ as early probable and latent multiple sclerosis, and $10 \%$ as possible multiple sclerosis. The mean age was 49 years, the mean age at onset was 34 years, and the mean duration of the disease was 15.4 years. The age standardised female to male ratio was 2:1.

The prevalence found in this survey does not differ significantly from that recorded in the first north east Scotland survey.

This study suggests that, firstly, the prevalence of multiple sclerosis in south east England is probably about 100/100 000 and, secondly, the latitudinal effect on the prevalence of multiple sclerosis in the United Kingdom is less appreciable than previously believed.
\end{abstract}

\section{Introduction}

In the United Kingdom all major epidemiological surveys of multiple sclerosis have been carried out in the north of England, Northern Ireland, or Scotland, ${ }^{1-9}$ and indeed Scotland has been surveyed more often than any other place in the world. A survey in Cornwall has been the only attempt to measure prevalence in the south of England. ${ }^{10}$ Table I summarises the main United Kingdom surveys and illustrates three points that are helpful in interpreting prevalence studies. Firstly, more recent surveys tend to show higher prevalences than do earlier surveys. ${ }^{11}$ For example, northern Scotland, studied in the early $1950 \mathrm{~s}$, recorded a prevalence of $67 / 100000,{ }^{3}$ whereas a study of north east Scotland two decades later produced a prevalence in excess of 120/100 000.' This increased prevalence over time was partly attributed to the better methods of ascertaining cases used in later surveys and also to longer survival times. " Secondly, repeated surveys of the same geographical area consistently produce higher prevalences with each subsequent survey. ${ }^{11}$ Table I shows that surveys of north east Scotland produced a $40 \%$ rise in prevalence over three surveys $s^{7-10}$ and Orkney a threefold increase in prevalence over four surveys. ${ }^{356}$ Thirdly, surveys of places with very small populations, like Orkney and Shetland, yield results of low precision..$^{12}$ In the first Shetland survey, for example, the $95 \%$ confidence limits ranged from 81 to $185 / 100000$.

As there is so little information about prevalence in the south of England, the most populated part of the United Kingdom, the prevalence for the United Kingdom is unknown, although it is generally accepted to be over $30-40 / 100000 .^{9}$ The prevalence in England is usually assumed to be lower than that in Scotland as the prevalence in the south is thought to be lower than that reported in

\footnotetext{
Department of Clinical Epidemiology and Social Medicine, St George's Hospital Medical School, London SW17 ORE

EDWARD $S$ WILLIAMS, $\mathrm{MB}$, MFCM, senior registrar in community medicine

Department of Neurology, Atkinson Morley's Hospital, Wimbledon, London SW20

RONALD O MCKERAN, MD, FRCP, consultant neurologist

Correspondence to: Dr Williams.
}

the north. ${ }^{13}$ The aim of this survey was to measure the age and sex specific prevalence for multiple sclerosis in the London Borough of Sutton, in south east England.

\section{Patients and methods}

\section{AREA}

The London Borough of Sutton covers $43 \mathrm{~km}^{2}$ and is $51^{\circ}$ north of the equator. The mid-year population estimate for Sutton in 1984 was $169600 .{ }^{14}$ Over the past three decades the size of the population has remained virtually constant. Sutton contains a higher proportion of people in social classes I and II than the national norm, and $47 \%$ of the population are in non-manual occupations, compared with $33 \%$ for Great Britain. ${ }^{14}$ Sixteen per cent of the population are aged over 65 and $4 \%$ were born in the new Commonwealth or Pakistan. The area is suburban and served by roughly 80 general practitioners. Most patients with neurological conditions are seen by one neurologist (RMCK) at St Helier or Atkinson Morley's hospitals, although some attend hospitals in inner London.

TABLE I-Summary of United Kingdom prevalence surveys of multiple sclerosis: $1950-80$

\begin{tabular}{|c|c|c|c|c|c|}
\hline Area & $\begin{array}{l}\text { Year } \\
\text { of } \\
\text { survey }\end{array}$ & $\begin{array}{l}\text { Surveyed } \\
\text { population }\end{array}$ & Cases & $\begin{array}{c}\text { Crude prevalence/ } \\
100000(95 \% \\
\text { confidence intervals) }\end{array}$ & $\begin{array}{l}\text { Standardised } \\
\text { prevalence } \\
\text { ratio }^{\star}\end{array}$ \\
\hline \multirow[t]{2}{*}{ Northern Ireland ${ }^{12}$} & 1951 & 1370709 & 700 & $51(47$ to 55$)$ & 62 \\
\hline & 1961 & 1425042 & 1158 & $81(77$ to 86$)$ & 100 \\
\hline \multirow{2}{*}{$\begin{array}{l}\text { North Scotand } \\
\text { Cornwall } \\
\end{array}$} & 1954 & 231116 & 154 & $67(56$ to 77$)$ & 76 \\
\hline & 1958 & 338770 & 214 & $63(54$ to 72$)$ & 68 \\
\hline \multicolumn{6}{|l|}{ Durham and } \\
\hline \multirow{5}{*}{$\begin{array}{l}\text { Northumberland }{ }^{4} \\
\text { Orkney }^{356}\end{array}$} & 1959 & 2308000 & 1156 & $50(47$ to 53$)$ & 56 \\
\hline & 1954 & 20746 & 23 & $111(65$ to 156$)$ & 124 \\
\hline & 1962 & 18531 & 33 & $178(117$ to 239$)$ & 200 \\
\hline & 1970 & 17077 & 40 & 234 (161 to 307$)$ & 284 \\
\hline & 1974 & 17462 & 54 & 309 (227 to 391$)$ & 384 \\
\hline \multirow{4}{*}{ Shetland 356} & 1954 & 18715 & 25 & $134(81$ to 185$)$ & 142 \\
\hline & 1962 & 17537 & 29 & 165 (105 to 226$)$ & 184 \\
\hline & 1970 & 17327 & 31 & 179 (116 to 242$)$ & 216 \\
\hline & 1974 & 18445 & 34 & $184(122$ to 246$)$ & 237 \\
\hline \multirow[t]{3}{*}{ North east Scotland ${ }^{7-9}$} & 1970 & 440176 & 557 & $127(116$ to 137$)$ & 153 \\
\hline & 1973 & 440227 & 634 & $144(133$ to 155$)$ & 175 \\
\hline & 1980 & 471000 & 839 & $178(165$ to 190$)$ & 221 \\
\hline
\end{tabular}

${ }^{\star}$ Calculated using 1961 Northern Ireland age specific prevalence.

\section{METHOD}

Having obtained approval from the local ethical committee, we used six sources to draw up a provisional nominal list of identified cases of multiple sclerosis. The social services department and the local branch of the Multiple Sclerosis Society provided names for the provisional list. All general practitioners in the borough were asked to supply information either by telephone or by letter. The department of neurology at Atkinson Morley's and St Helier hospitals searched through case notes and also provided a list of patients who had had a visual evoked response investigation in the previous three years. Community nurses provided a list of patients. The South West and South East Thames Regional Health Authorities and the National Hospital for Nervous Diseases made a computer search for Sutton residents discharged from hospital with any mention of multiple sclerosis in the previous 10 years.

Patients' names were included on the list if they had been labelled as having multiple sclerosis by any one of the six sources of ascertainment, and also if they were usually resident in Sutton on the day prevalence was calculated. Patients in long term residential care whose usual address was Sutton were admitted to the list. The 1981 London Borough of Sutton street index was used to verify an address as being within the survey area.

Clinical information on all 217 patients on the provisional list was extracted from 183 hospital case notes and 34 general practitioners' records. From this information patients were classified by the neurologist (RMCK) 
into diagnostic groups using the classification system of Allison and Millar of probable multiple sclerosis, early probable and latent multiple sclerosis, and possible multiple sclerosis. ${ }^{1}$ The Allison and Millar classification was used to allow comparisons with previous United Kingdom surveys. ${ }^{12478}$

We calculated a standarised prevalence ratio to take account of differences in age among the surveyed populations presented in table I. As age specific rates are not generally available an indirect method was applied, using the age specific rates from the 1961 Northern Ireland survey. ${ }^{2}$

\section{Results}

The Sutton branch of the Multiple Sclerosis Society provided an up to date list of 132 members, of whom 91 were eligible for inclusion in the provisional list. The social services identified 169 clients with diagnosed multiple sclerosis from their handicap register, of whom 110 qualified for inclusion. Of the 80 general practitioners practising in the borough, 67 $(84 \%)$ responded, identifying 71 eligible patients. The community nursing service identified 63 patients, and the hospital provided 119 eligible names. Hospital Activity Analysis data produced 77 eligible patients. The provisional nominal list prepared from the data gathered contained 217 names. Of these, 67 were identified by only one source-that is, 42 by the hospital, 10 by general practitioners, 10 by Hospital Activity Analysis, two by community nurses, two by social services, and one by the Multiple Sclerosis Society. Forty seven patients were identified by two sources, 43 by three sources, and 60 by four or more sources.

The greatest number of cases was yielded by hospitals and social services, identifying $130(60 \%)$ and $122(56 \%)$ respectively; together they yielded 193 $(89 \%)$ of the cases. Hospitals and general practitioners together yielded 171 $(79 \%)$ of the cases. During the classification stage of the survey 22 patients were excluded-nine because of a wrong address, eight with a wrong diagnosis, and five who had died.

On the day prevalence was calculated, 1 January 1985 , 195 people with multiple sclerosis were usually resident in Sutton, including six patients in long term care. The overall prevalence was $115 / 100000$ population; the prevalence for the different diagnostic groups is shown in table II. The age standardised ratio of women to men was $2: 1$. Table III shows the age specific rates; rates for women were higher in all age groups over 25 years, and the highest rate for both men and women, 146 and 343/100 000 respectively, occurred in the 45-54 age group.

The age range of patients was $20-82$ years, with a mean of 49 (SD 14.4); the mean age for women was $50(14 \cdot 7)$ and for men $46 \cdot 4(13 \cdot 4)$. Table $\mathrm{V}$ shows the age and year of onset of multiple sclerosis. The mean age at onset was $34 \cdot 1$ years $(10 \cdot 5)$ (range 14-61) for the whole group, 33.7 (10.9) for women, and $34 \cdot 8(9 \cdot 6)$ for men.

The mean duration of disease from onset to day of prevalence for both sexes was 15.4 years $(11 \cdot 0)$, for women 16.7 years $(11 \cdot 0)$, and for men 12.2 years $(9 \cdot 9)$. The longest recorded duration was 52 years; $29(25 \%)$ women and $7(6 \%)$ men had had multiple sclerosis for more than 25 years.

TABLE II-Prevalence of multiple sclerosis in London Borough of Sutton by diagnostic group and sex

\begin{tabular}{lcc}
\hline Groups & $\begin{array}{c}\text { No of } \\
\text { patients }(\%)\end{array}$ & $\begin{array}{c}\text { Prevalence/100 000 } \\
\text { (95\% confidence intervals) }\end{array}$ \\
\hline Probable multiple sclerosis & $147(75)$ & $87(73$ to 100$)$ \\
Early probable multiple sclerosis & $29(15)$ & $17(11$ to 23$)$ \\
Possible multiple sclerosis & $19(10)$ & $11(6$ to 16$)$ \\
All groups & $195(100)$ & $115(99$ to 131$)$ \\
Total men & $60(31)$ & $74(55$ to 93$)$ \\
Total women & $135(69)$ & $152(126$ to 178$)$ \\
\hline
\end{tabular}

TABLE III-Prevalence of multiple sclerosis per 100000 population by age and sex in London Borough of Sutton *

\begin{tabular}{|c|c|c|c|c|c|c|}
\hline \multirow{2}{*}{$\begin{array}{l}\text { Age group } \\
\text { (years) }\end{array}$} & \multicolumn{2}{|c|}{ Men } & \multicolumn{2}{|c|}{ Women } & \multicolumn{2}{|c|}{ Total } \\
\hline & No & Rate & No & Rate & No & Rate \\
\hline $15-24$ & 3 & $24 \cdot 8$ & 2 & $15 \cdot 9$ & 5 & $20 \cdot 2$ \\
\hline $25-34$ & 8 & $65 \cdot 6$ & 22 & $177 \cdot 4$ & 30 & 121.9 \\
\hline $35-44$ & 16 & 135.6 & 28 & $241 \cdot 7$ & 44 & $189 \cdot 1$ \\
\hline $45-54$ & 14 & $145 \cdot 8$ & 35 & 343.4 & 49 & $246 \cdot 2$ \\
\hline $55-64$ & 12 & $130 \cdot 4$ & 24 & $235 \cdot 3$ & 36 & 185.6 \\
\hline $65-74$ & 6 & $100 \cdot 0$ & 17 & $200 \cdot 0$ & 23 & 158.6 \\
\hline$\geqslant 75$ & 1 & $24 \cdot 4$ & 7 & $82 \cdot 4$ & 8 & $63 \cdot 5$ \\
\hline All ages & 60 & $74 \cdot 2$ & 135 & 152.0 & 195 & $115 \cdot 0$ \\
\hline
\end{tabular}

^OPCS 1984 mid-year estimates used for age group denominators.
TABLE IV-Comparison of survey results: Sutton survey and first north east Scotland survey

\begin{tabular}{|c|c|c|}
\hline & Sutton & $\begin{array}{l}\text { North east } \\
\text { Scotland }\end{array}$ \\
\hline Reference population & 169600 & 440176 \\
\hline Total cases & 195 & 557 \\
\hline \multicolumn{3}{|l|}{ Overall prevalence/ 100000} \\
\hline ( $95 \%$ confidence intervals) & 115 (99 to 131$)$ & 127 (116 to 137$)$ \\
\hline Probable multiple sclerosis (\%) & $147(75)$ & $310(56)$ \\
\hline \multicolumn{3}{|l|}{ Early probable and latent } \\
\hline multiple sclerosis $(\%)$ & $29(15)$ & $154(28)$ \\
\hline Mean age & $49 \cdot 0$ & $48 \cdot 2$ \\
\hline Mean duration & $15 \cdot 4$ & $14 \cdot 4$ \\
\hline Mean age at onset & $34 \cdot 1$ & $34 \cdot 2$ \\
\hline Mean annual incidence $/ 100000$ & 5.0 & $5 \cdot 3^{\star}$ \\
\hline Proportion of women $(\%)$ & 69 & 62 \\
\hline $\begin{array}{l}\text { Standardised prevalence ratio } \\
\text { (95\% confidence intervals) }\end{array}$ & $129(111$ to 147$)$ & $153(140$ to 166$)$ \\
\hline
\end{tabular}

^From second north east Scotland survey calculated from period 1959-73.

† Standarised prevalence ratio in Northern Ireland $1961=100$.

TABLE V-Age at onset and year of onset of multiple sclerosis in $194^{\star}$ patients in Sutton

\begin{tabular}{cccc}
\hline Age group (years) & No patients & Calendar year & No of patients \\
\hline $14-19$ & 10 & $1931-3$ & 1 \\
$20-24$ & 29 & $1934-6$ & 1 \\
$25-29$ & 28 & $1937-9$ & 0 \\
$30-34$ & 27 & $1940-2$ & 1 \\
$35-39$ & 31 & $1943-5$ & 3 \\
$40-44$ & 28 & $1946-8$ & 3 \\
$45-49$ & 22 & $1949-51$ & 5 \\
$50-54$ & 13 & $1952-4$ & 10 \\
$55-59$ & 5 & $1955-7$ & 8 \\
$60-64$ & 1 & $1958-60$ & 7 \\
& & $1961-3$ & 9 \\
& & $1964-6$ & 17 \\
& & $1967-9$ & 19 \\
& & $1970-2$ & 14 \\
& & $1973-5$ & 19 \\
& & $1976-8$ & 24 \\
& & $1979-81$ & 35 \\
\end{tabular}

*Data missing in one case.

The estimated mean annual incidence for the nine years 1976-84 was $5 / 100000$ population. This arbitrary period was chosen because it yielded sufficient cases (77) to give a reasonably precise estimate of the annual mean number and yet was thought to be not too long to be seriously biased by cases lost to follow up through death and migration. A crude estimate of the mean duration from onset to death can be obtained by using Poskanzer's indirect method of doubling duration from onset to the day of prevalence ${ }^{6}$; in the present study this yielded an estimated mean duration from onset to death of 31 years.

\section{Discussion}

A crucial factor in epidemiological surveys of multiple sclerosis is complete and accurate ascertainment of cases. Incomplete ascertainment leads to underestimating the prevalence and, therefore, makes comparison between surveys difficult to interpret as observed differences may reflect incompleteness rather than real differences in prevalence. A key aspect of the design of epidemiological surveys of multiple sclerosis is the choice of a population at risk that yields an accurate estimate of true prevalence. Surveys of very large populations, such as Northern Ireland ${ }^{12}$ and Durham and Northumberland, ${ }^{4}$ are biased by incomplete ascertainment, whereas surveys of very small populations, such as those of Orkney and Shetland, are subject to the imprecision associated with a large sampling error. ${ }^{3}$ The population chosen for study should be a compromise between these two opposing sources of inaccuracy.

In this study the population was of a manageable size, allowing fairly detailed methods of ascertainment. The social service department and hospitals were the most successful sources and appeared to identify two different groups of cases. Hospital Activity Analysis data were found to be a valuable source and may form the starting point of future surveys in the United Kingdom. Standardising for 
age confirmed the view of Poskanzer that differences in age structure have relatively little effect on observed differences between surveys. ${ }^{6}$

The overall prevalence of $115 / 100000$ is the third highest recorded for a first survey of an area in the United Kingdom, exceeded only by 127 in north east Scotland ${ }^{7}$ and 134 in Shetland. ${ }^{3}$ The Shetland prevalence, however, is subject to the imprecision caused by a large sampling error mentioned earlier. The method of ascertainment in the present survey, which used Hospital Activity Analysis data and social services information, differed widely from methods used in the earlier surveys of Northern Ireland, north Scotland, and Durham and Northumberland so that comparison was not worth while. The most valid comparison was with the first survey of north east Scotland, which also used detailed methods of ascertainment.

Table IV compares the main results of the two surveys. Overall prevalence was slightly but not significantly higher in north east Scotland; age standardisation, however, accentuated the difference. Mean age, mean age at onset of multiple sclerosis, mean duration, and estimated mean incidence were remarkably similar in the two surveys. Sutton had a higher percentage of women and more people with probable multiple sclerosis and fewer with early probable or latent multiple sclerosis. Classification bias may have accounted for some of the difference between diagnostic groups as different methods of classification were used; in north east Scotland $77 \%$ of patients were classified after a physical examination, whereas in Sutton patients were classified using information abstracted from medical records. The second and third surveys of north east Scotland produced prevalences of 144 and 178/100 000 respectively, which were significantly higher than the prevalance in Sutton. How much of these differences were due to the effect of repeated studies, however, is unclear. ${ }^{25689}$

Using a nine year average mean is a crude method for estimating incidence. It assumes no change in the disease over time and is biased by people lost to follow up through death and migration. Using data for the latest nine years probably provided sufficient cases for a reasonable estimate of incidence. Interestingly, the mean annual incidence in north east Scotland in $1973(5 \cdot 3)$ was similar to that of Sutton in $1984(5 \cdot 0)$.

In support of Limburg's hypothesis that the frequency of multiple sclerosis increases with the distance of the surveyed area from the equator, ${ }^{15}$ Acheson proposed the existence of a simple linear relation between prevalence and geographical latitude in Europe, prevalence being higher in the north and lower in the south." A comparison of the prevalence in north Scotland and Cornwall produced in the 1950s, however, failed to show any significant north-south gradient. Moreover, the prevalence found in our survey suggests that the latitudinal effect in the United Kingdom may be less than is generally accepted. Moreover, in a household survey of disabled people in the London Borough of Kensington and Chelsea carried out under the Chronically Sick and
Disabled Persons Act during the early 1970s the number of people who reported their disability as caused by multiple sclerosis gave a prevalence of $130 / 100000,{ }^{16}$ which was similar to the prevalence recorded in Scotland.

We conclude that to date the evidence provided by United Kingdom surveys of a north-south gradient in prevalence is less than convincing. Although it is generally accepted that the United Kingdom has a relatively high prevalence, usually taken as over 30$40 / 100000$, on the basis of this survey the prevalence for south east England is around 100/100 000. This prevalence may well apply more widely in the United Kingdom, but to establish this supposition will require further investigation.

We thank Mary Spencely, district medical officer of Merton and Sutton District Health Authority, for her encouragement in setting up this survey; Michael Warren, Ross Anderson, and David Jones for their advice; Grace Bellingham of the Sutton branch of the Multiple Sclerosis Society and Ken Thornton of Sutton Social Services for their cooperation in collecting data; Janet Ashton, Atkinson Morley's Hospital, and Sally Anne Jones, the National Hospital for Nervous Diseases, for help in tracing hospital notes; Pamela Class for typing the manuscript; and our colleagues in general practice for their willing cooperation in supplying information and allowing us access to their notes.

\section{References}

Allison RS, Millar JHD. Prevalence of disseminated sclerosis in Northern Ireland. Ulster Med 7 1954;23:5-27

2 Millar JHD. Multiple sclerosis in Northern Ireland. In: Clifford Rose F, ed. Clinical epidemiologv. Tunbridge Wells: Pitman Medical, 1980:222-7

3 Sutherland JM. Observations on the prevalence of multiple sclerosis in northern Scotland. Brain 1956;79:635-54.

4 Poskanzer DC, Schapira K, Miller H. Epidemiology of multiple sclerosis in the counties of Northumberland and Durham. I Neurol Neurosurg Psychiatry 1963;26:368-76.

5 Fog M, Hyllested K. Prevalence of disseminated sclerosis in Faroes, the Orkneys and Shetlands. Acta Neurol Scand 1966:42 (suppl 19):9-11

6 Poskanzer DC, Preaney LB, Sheridon JL, Kondy JY. Multiple sclerosis in the Orkney and Shetland Islands: epidemiology, clinical factors and methodology. 7 Epidemiol Community Health 1980;34:229-39.

Shepherd DI, Downie AW. Prevalence of MS in north-east Scotland. Br Med f 1978;ii:314-6.

8 Shepherd DI, Downie AW. A further prevalence study of multiple sclerosis in north-east Scotland. 7 Niurol Neurosurg Pswchiatry 1980;43:310-5.

Downie AW. The Chief Scientist reports . . . Multiple sclerosis in north east Scotland. Health Bull (Edinb) 1984;42/3:1561-6.

10 Hargreaves ER. Epidemiological studies in Cornwall. Proceedings for the Society of Medicine 1961;54:209-16.

11 Acheson ED. The epidemiology of multiple sclerosis, the pattern of the disease. In: Matthews WB, Achewon I:D, Barchelor JR, Weller RO, eds. McAlpine's muluple sclerosis. Edinburgh: Churchill Livingstone, 1985:3-26.

12 Hoinville G, Jowqell R. Survey research practice. London: Heineman Educational Books, 1977:60-1.

13 Kurtze JF. The geographic distribution of MS: an update with special reference to Europe and the Mediterranean region. Acta Neurol Scand 1980;62:65-80

14 Office of Population Censuses and Surveys. Registrar General, Scotland. Census 1981. Key statistics for local authorities in Great Britain. London: HMSO, 1984

15 Limburg CC. The geographic distribution of multiple sclerosis and its estimated prevalence in the United States. Proceedings of the Association for Research into Nervous and Mental Disease 1950;28:15-24

16 Warren MD, Knight R. Physically disabled people living at home: a study of numbers and needs. Report on Health and Social Subjects, DHSS. London: HMSO, 1978.

(Accepted 19 May 1986

\section{Captopril in elderly patients with heart failure}

There are many reports on captopril but few data on its use in the elderly. We report our experience with captopril in an open study of an elderly population with heart failure.

\section{Patients, methods, and results}

Thirty elderly patients (mean age 81.6 (range 71-92) years) with congestive cardiac failure that had not responded to frusemide $40-120 \mathrm{mg}$ or its equivalent were recruited into an open 12 week study of captopril. Cardiac failure had been present for an average of $11.9(0.5-48)$ months. Seventeen patients were New
York Heart Association class II, eight class III, and five class IV. Sixteen were in-patients at the start of the study, and 14 were outpatients.

Eighteen patients completed the study; the remaining 12 were withdrawn because of non-compliance (failure to take more than $80 \%$ of the tablets) (five patients), intractable heart failure that did not improve when they took captopril (two), death from cardiac infarction (one), death from respiratory failure (one), vertebrobasilar insufficiency (one), death from gastrointestinal haemorrhage (one), and disseminated carcinoma (one). Multiple disease is a feature of this age group, and the deaths were probably unrelated to the drug.

The cardiac output was measured by a computerised densitometer with a diachromatic earpiece ${ }^{1}$ and was taken to be the mean of three values. The dye was injected rapidly into the antecubital vein. The first dose of captopril $(6.25 \mathrm{mg})$ was administered orally and the patient monitored in the supine position for three hours. Captopril $6.25 \mathrm{mg}$ twice daily was then taken until the next assessment, when the dose was increased to $25 \mathrm{mg}$ twice daily for the next four weeks.

Thereafter the dose was increased if the cardiac failure was not controlled. If there was evidence of fluid retention the diuretic dose was increased but reduced if 